\title{
Parental compliance for speech therapy of their hearing- impaired children using cochlear implants
}

\author{
Amna Asghar ${ }^{1}$, Tayyaba Dawood ${ }^{1}$, G hulam Saqulain ${ }^{2}$, Aqsa Irum³ ${ }^{3}$ Rabia Zaman Khan ${ }^{4}$, Hina Saeed Ch. ${ }^{1}$, \\ N oreen Anwar ${ }^{1}$ \\ ${ }^{1}$ C linical Audiologist, E N T U nit, Audiology D epartment, SG RH /FJM U , L ahore, ${ }^{2} \mathrm{H}$ ead of D epartment EN T U nit CD A H ospital, I slamabad, \\ ${ }^{3}$ Audiology L ecturer, ENT U nit, Audiology Department, KEM U/M ayo H ospital, Lahore, ${ }^{4}$ Associate Professor, ENT Unit, SGRH/FJMU, \\ Lahore. \\ Correspondence to:T ayyaba D awood, Email: taibadawood3@gmail.com
}

\begin{abstract}
Background: C ochlear implant is a miraculous surgery to improve hearing in profound hearing-impaired children who derive no benefit from hearing aids and consequently present with speech and language disability. This study aims to explore the parental perspective regarding compliance to speech therapy and its potential benefit in hearing-impaired children with cochlear implantation. This will help understand parental concerns and plan recommendations for providing appropriate speech therapy sessions after cochlear implantation.

Subjects and methods: T his cross-sectional study using purposive sampling recruited 217 parents of hearing impaired cochlear implanted children of both genders, aged 1 to 15 years. Sample was collected from Audiology D epartment of Riphah International U niversity, Combined Military Hospital, Bahria T own Hospital and Alam Audiology Clinic, L ahore, Pakistan over a period of 6 months. Basic demographic sheet and self-structured questionnaire was used for data collection. SPSS V ersion 22 was used for data analysis.

Results: Results revealed that both parents of 120 (55.3\%) male and 97 (44.7\%) female cochlear implanted children entered the study. A poor compliance was noted with only $88(40.55 \%)$ parents got their children consulted with a speech therapist for post implant needs and of these only $75(84.23 \%)$ received regular speech therapy. There was significant association of those who received hearing aid trial and consultation to speech therapist $(p=0.01)$ and length of speech therapy with regular therapy sessions $(p=0.03)$, speech language improvement with the thought that regular speech therapy was important $(p=0.04)$

Conclusion: By and large parents are not very compliant to speech therapy needs of their implanted children with only $40.55 \%$ consulted speech language therapists and remaining remained indifferent. Of the $40.55 \%$ who consulted speech language therapists $84.23 \%$ followed speech therapy for their children. Study also revealed a significant relationship between regular speech therapy sessions and early speech and language development.
\end{abstract}

\section{INTRODUCTION}

H earing impairment $(\mathrm{HI})$ is quite common with about $10 \%$ of the population affected globally, ${ }^{1}$ a much higher prevalence is expected being a developing country with lack of reliable local prevalence data and lack of universal neonatal screening, one study reported a prevalence of $7.9 \%$ in rural areas. ${ }^{2}$ Children with $\mathrm{HI}$ suffer from Speech-L anguage and communicational impairments due to inability to perceive spoken language, and cochlear implants have given these children access to spoken language. ${ }^{3} \mathrm{H}$ earing sense is one of the most important sense among our five senses that give us access to hear various types of sounds in the world around us. ${ }^{4}$ It is significantly important for spoken language and other communication skills.

\footnotetext{
C onflict of interest: T he authors declared no conflict of interest exists.

Citation: Asghar A, D awood T, Saqulain G, Irum A, Khan RZ, Ch. H S, et al.

Parental compliance for speech therapy of their hearing impaired children using cochlear implants. J Fatima Jinnah M ed U niv. 2021; 15(2):58-62.
}

W hen hearing loss is left undetected, children's speech and language development lags behind. ${ }^{5} \mathrm{H}$ earing aids (HA) are indicated for various levels and types of hearing loss, however the utility of hearing aids have limited utility when patient has severe to profound hearing loss. ${ }^{6}$ Role of cochlear implant comes in case of children who suffer sensorineural hearing loss on both sides with $80 \mathrm{~dB} \mathrm{HI}$ following around 6 months of rehab with use of $\mathrm{H} \mathrm{A.}^{7}$

The cochlear implant $(\mathrm{Cl})$ is an assistive electronic equipment that plays a key role to provide auditory stimulation and replaces the non-functional transduction system of tiny cochlear hair cells. $\mathrm{H}$ owever, acquiring the auditory skills depends on the integrity of peripheral and central auditory pathways, user's psychosocial status and involvement of the user's relatives' involvement in the whole therapeutic process of speech and language development. ${ }^{8}$ Thus, using cochlear implant alone does not ensure the progress and adequate communicative development. Being a 
multidisciplinary task interaction between child and parent can predict performance. ${ }^{9}$

$W$ ith the establishment of public sector Cochlear Implant center in Pakistan in Islamabad. ${ }^{10}$ the need to provide support to these families is being essentially felt and with lack of local literature on the subject. Cochlear implantation and its rehabilitation process is not without stress especially after implantation. ${ }^{11}$

This study is aimed to explore the parental perspective as regards compliance to speech therapy and its potential benefit in hearing impaired children with cochlear implantation.

\section{SUBJ ECTS AND METHODS}

The cross-sectional survey was conducted at Audiology D epartment of Riphah International U niversity L ahore Campus over a period of 6 months from $1^{\text {st }}$ January 2017 to $30^{\text {th }}$ June 2017. Sample included parents (including both mothers and fathers) of 217 hearing impaired children with cochlear implantation of both genders aged 1-15 years. Age of 1 year was included since it falls in FDA approved lower limit of age. ${ }^{12}$ Sample was recruited using purposive sampling, from Combined Military Hospital, Pakistan Cochlear Implant Center, Bahria Town Hospital and Alam Audiology Clinic, Lahore. Children with any other disability and those with post-implant complications were excluded. Sample size of $n=217$ was calculated using formula:

$$
N=\frac{z_{\alpha / 2}^{2} * \boldsymbol{p} *(1-p) * D E F F}{d^{2}}
$$

Where

$\alpha=0.05$, effect size (DEFF) $=1$,

Absolute precision $(\mathrm{d})=0.05$ and

Prevalence proportion of disease as 0.17

A basic demographic sheet and self-structured questionnaire were used for data collection. Questionnaire was developed consulting different literature and sent to three experts including a speech language pathologist, an audiologist and an otolaryngologist. Thirdly these items were tested for relevance, ambiguity, clarity and simplicity from the experts with positive responses coded 1 and negative coded 0 . This revealed a valid questionnaire with content validity of tool with $M$ ean \pm SD for relevance, clarity, simplicity, and ambiguity being $2.25 \pm 0.15$ each with light variability for individual expert rating of content validity. Study was conducted after obtaining ethical approval of Institutional Research Board of
Riphah International U niversity and permission from the other institutions for case collection and informed consent of the parents of $\mathrm{HI}$ children.

Study explored parental perspective as regards compliance to speech therapy and its potential benefit in the sample population. For this purpose, compliance was defined as post implant consultation with speech therapist and those who received therapy did that at different settings including the study settings. Parental perspectives were evaluation after a minimum period of one year post implant

Q uestionnaires were applied to the participants by three of the researchers themselves to alley any difficulties in understanding the questions. Speech level of child was taken into account at 4 levels including no speech, world level, phrase level and sentence level.

$D$ ata collected was analysed using SPSS version 22 using descriptive statistics. D escriptive statistics including frequency and percentages were calculated. Chi-square test was applied to see associations among variables and $p$-value of $\varangle .05$ was considered significant.

\section{RESULTS}

Current study to evaluate parental perspective in connection with compliance to speech therapy for their cochlear implanted children and its potential benefit in 217 hearing impaired children with cochlear implantation of which most 120 (55.3\%) were males and $(41.6 \%)$ between $6-10$ years of age. Majority of mothers $171(78.6 \%) \&$ fathers $172(79.3 \%)$ were illiterate and $143(65.9 \%)$ were housewives (T able 1).

\begin{tabular}{|c|c|}
\hline Characteristics & $n(\%)$ \\
\hline \multicolumn{2}{|l|}{ Child D emographics } \\
\hline \multicolumn{2}{|l|}{ Gender of child } \\
\hline M ale & $120(55.3)$ \\
\hline Female & $97(44.7)$ \\
\hline \multicolumn{2}{|l|}{ Age of child (years) } \\
\hline $01-05$ & $86(39.6)$ \\
\hline $06-10$ & $90(41.6)$ \\
\hline $11-15$ & $41(18.9)$ \\
\hline \multicolumn{2}{|l|}{ Parental D emographics } \\
\hline \multicolumn{2}{|l|}{ Mothers' education level } \\
\hline Literate & $171(78.6)$ \\
\hline Illiterate & $46(21.2)$ \\
\hline \multicolumn{2}{|l|}{ Mothers' occupation } \\
\hline H ousewives & $143(65.9)$ \\
\hline W orking & $74(34.1)$ \\
\hline \multicolumn{2}{|l|}{ Fathers' education level } \\
\hline Literate & $172(79.3)$ \\
\hline Illiterate & $45(20.7)$ \\
\hline \multicolumn{2}{|l|}{ Economic status } \\
\hline L ower class & $16(7.4)$ \\
\hline M iddle class & $140(64.5)$ \\
\hline U pper class & $61(28.1)$ \\
\hline
\end{tabular}


Table 2: Response distribution of parent to items of questionnaire $(n=217)$

\begin{tabular}{|c|c|c|c|}
\hline Group & Q uestions & Response category & $n(\%)$ \\
\hline \multirow{14}{*}{$\begin{array}{l}\text { Compliance of parents } \\
\text { for speech therapy of } \\
\text { their implanted } \\
\text { children }\end{array}$} & \multirow{3}{*}{$\begin{array}{l}\text { D o you think that regular speech therapy is important for early speech } \\
\text { and language development? }\end{array}$} & Yes & $175(80.6)$ \\
\hline & & No & $16(7.4)$ \\
\hline & & U ncertain & 26 (12) \\
\hline & \multirow{2}{*}{$\begin{array}{l}\text { H ave you ever consulted a speech therapist for your child's post-implant } \\
\text { therapy needs? }\end{array}$} & Yes & $88(40.55)$ \\
\hline & & No & $129(59.45)$ \\
\hline & \multirow{2}{*}{$\begin{array}{l}\text { D id the child receive regular speech therapy sessions? } \\
(n=88)\end{array}$} & Yes & $75(85.23)$ \\
\hline & & $\mathrm{No}$ & $13(14.77)$ \\
\hline & \multirow{3}{*}{$\begin{array}{l}\text { H ow long has your child received speech therapy? } \\
(n=75)\end{array}$} & $0.6 \mathrm{M}$ onths & $30(40)$ \\
\hline & & $1-2$ years & $32(42.67)$ \\
\hline & & 3-4 years & $13(17.33)$ \\
\hline & \multirow[t]{2}{*}{ W hat was frequency of therapy sessions? } & W eekly & $40(53.33)$ \\
\hline & & M onthly & $35(46.67)$ \\
\hline & \multirow{2}{*}{$\begin{array}{l}\text { Did caregiver follow the instructions and time for therapy at home as per } \\
\text { therapist's recommendation? }\end{array}$} & Yes & $45(60)$ \\
\hline & & No & $30(40)$ \\
\hline \multirow{4}{*}{$\begin{array}{l}\text { Parental perspective of } \\
\text { speech therapy } \\
\text { following implantation }\end{array}$} & \multirow[t]{3}{*}{ D id your child's speech and language improved with speech therapy? } & Yes & $55(73.34)$ \\
\hline & & $\mathrm{No}$ & $10(13.33)$ \\
\hline & & U ncertain & $10(13.33)$ \\
\hline & \multirow[t]{4}{*}{ W hat is $L$ evel of speech and language after implant? } & N o Speech & $40(18.43)$ \\
\hline \multirow{5}{*}{$\begin{array}{l}\text { Potential benefits of } \\
\text { speech therapy } \\
\text { following implantation }\end{array}$} & & W ord level & $62(28.57)$ \\
\hline & & Phrase level & $65(29.95)$ \\
\hline & & Sentence level & $50(23.04)$ \\
\hline & \multirow[t]{2}{*}{ Can child communicate independently in social environment? } & Yes & $115(53)$ \\
\hline & & $\mathrm{No}$ & $102(47)$ \\
\hline
\end{tabular}

Responses of the parents to questionnaire items revealed that $137(63.1 \%)$ children < 3years of age and $80(36.9 \%)$ between 3-5 years, as regards speech before implantation, majority 129 $(59.4 \%)$ did not have any speech, followed by word level speech in $73(33.5 \%)$ and only $15(6.9 \%)$ had phrase level speech development (T able 2). Cochlear implantation was done at mean age of $6.57 \pm 3.97$ years with majority $148(68.2 \%)$ being of $5-8$ years old, while only $69(31.8 \%)$ were implanted at 1-4 years of age. $W$ hile the assessment for parental perspective regarding compliance was done following a minimum period of 1 year post-implantation.

Investigation on parental compliance for speech therapy of their hearing impaired children using cochlear implants in current study revealed that only 88 $(40.55 \%)$ parents consulted speech therapists. L ow literacy rate of parents and uncertainty regarding speech results might have resulted in non-compliance of the remaining 129 (59.45\%) of parents.

\section{DISCUSSION}

Speech therapy and regular follow-up can be of a big help to cochlear implanted children. Most of the participants' children were in the age range of 6-10 years and majority were males. M ost $(64.5 \%)$ of the participants' parents belonged to middle class and literate while more than $65 \%$ mothers were housewives. Amano et al ${ }^{13}$ conducted a study regarding significance of early identification of hearing loss and effects of cochlear implantation on normal development of speech and language, reported that children must be diagnosed in early age and the results of this study are approximately consistent. In the current study parental perspective revealed more than half children were diagnosed at before 3 years of age while remaining were diagnosed between 3 to 5 years. ${ }^{14}$

Patient responses in the current study revealed normal milestone development except speech as no speech level in 59\% before receiving a cochlear implant but a rapid growth was seen in speech and language following implantation. $W$ hen parents were asked about speech therapist consultation majority responded positively. M aximum children got speech sessions only for 1-2 years and frequency was weekly. Children who are born deaf can have the maximum improvement if they are implanted at an early age, preferably before 2 years, keeping in view the benefit of period which is sensitive for auditory development. ${ }^{15} \mathrm{H}$ ence, the longer profound $\mathrm{HL}$ persists, the less likely are the benefits going to be. Also, person who recognizes speech and language, may receive correspondingly more benefit from cochlear implant. $\mathrm{H}$ amerschmidt et al ${ }^{16}$ reported the importance of speech therapy after cochlear implantation that says developing intelligible speech can be faster and there are greater chances of better success in those children who receive speech therapy right after implantation than those who undergo implantation but receiving no therapy. A scoping review conducted by $\mathrm{H}$ uttunen and $\mathrm{C}$ oauthors ${ }^{17}$ to check out success rate of 
speech intelligibility with comparison to mapping and speech therapy sessions after cochlear implantation. The results summarized in the review have similarity to the responses of this current study that shows a significant importance of speech therapy. Further it was observed that improvement and increase in speech outcomes is present in those who were regular in sessions, following their therapist's instructions and recommendations with word, phrase and sentence level in their children as $29 \%, 30 \%$ and $23 \%$ consequently. Speech and language was as per hearing age in $60 \%$ of children and 53\% parents reported as independent social communication of their children was present after the speech sessions in the current study. Hence, Parental support and family motivation are most important factor after cochlear implant for the development of speech. ${ }^{18}$ After some research $\mathrm{C}$ hang et $a^{18}$ evaluated benefits of age of implant and hearing aid trial on speech and language after Cochlear Implant that is directly hel pful for the learning of child.

Prathiba conducted an observational study on the relationship of speech level compared with the regularity in speech sessions that explains if child is actively participating in speech sessions and family is motivated it will contribute much in achieving a higher level of speech. ${ }^{19}$ T he current study also supports the evidence as those who were regular in their sessions' duration were positively associated. In addition, they were so improved that those children achieved phrase level in first few years of their implant surgery. They reported that their children can now independently communicate in social environment and their child's speech is average. ${ }^{19}$

Current investigation revealed that the earlier is the age of implantation followed by regular speech therapy sessions has vital role in speech \& language development. Those parents who consulted speech therapist, received therapy after implantation with ample timing and compliance to instruction of speech therapist got the maximum benefit from the implant. T his study also give suggestion for further research in this area.

\section{CONCLUSIONS}

By and large parents are not very compliant to speech therapy needs of their implanted children with only $40.55 \%$ consulted speech language therapists and others remaining remained indifferent.

Of the $40.55 \%$ who consulted speech language therapists $84.23 \%$ followed speech therapy for their children. Study also revealed an insignificant relationship between the age of implantation and consultation to the speech therapist while there was a significant relationship between regular speech therapy sessions and early speech and language development.

\section{REFERENCES}

1. Kennedy CR, M CC ann DC, Campbell MJ, Law CM, Mullee $M$, Petrou $S$, et al. L anguage ability after early detection of permanent childhood hearing impairment. $\mathrm{N}$ ew Eng J Med. 2016;34(20):2131-14.

2. Elahi M M, Elahi F, Elahi A, Elahi SB. Paediatric hearing loss in rural Pakistan. J O tolaryngol. 1998;27(6):348-53.

3. Kral A, O'D onoghue GM. Profound deafness in childhood. N ew Eng J M ed. 2017;363(15):1438-50.

4. Moret ALM, Bevilacqua MC, Costa OA. Implante coclear: audição e linguagem em crianças deficientes auditivas prélinguais. Pró-Fono R Atual. Cient. 2007; 19(3):295-304.

5. Anneke $M$, Vermeulen $T$. Reading comprehension of deaf children with cochlear implant. Int J Pediatr O torhinolaryngol. 2018;1(22):12-18.

6. Schuster-Bruce J, Gosnell E. Conventional hearing aid indications and selection. In: StatPearls [Internet]. T reasure Island (FL): StatPearls Publishing; 2021. Available from: https://www.ncbi.nlm.nih.gov/books/N BK 567712/

7. Szyfter W, Karlik M, Sekula A, H arris S, G awęcki W. Current indications for cochlear implantation in adults and children. O tolaryngol Pol. 2019;73(3):1-5.

8. Bosdriesz JR, Stam M, Smits C, K ramer SE. Psychosocial health of cochlear implant users compared to that of adults with and without hearing aids: Results of a nationwide cohort study. Clin Otolaryngol. 2018;43(3):828-834. DOI: 10.1111/coa.13055.

9. M arkman T M, Q uittner AL, E isenberg LS, T obey EA, T hal D, Niparko JK. Language development after cochlear implantation: an epigenetic model. J N eurodev Disord. 2011; 3(4): 388-404.

10. Ahmed J, Saqulain G, K han M IJ, K ausar M. Complications of Cochlear Implant Surgery: A Public Implant Centre Experience. Pak J M ed Sci. 2021;37(5):1519-1523.

11. Punch $R, H$ yde $M B$. Rehabilitation efforts and stress in parents of children with cochlear implants. Aust N Z J Audiol. 2010; 32(1).

12. M iyamoto RT, Colson B, Henning S, Pisoni D. Cochlear implantation in infants below 12 months of age. W orld J O torhinolaryngol H ead N eck Surg. 2018;3(4):214-218.

13. Amano $K$ A, Hosom J-P. A review of research on speech intelligibility and correlation with acoustic features. Center for Spoken L anguage U nderstanding. 2011;19(4):313-16.

14. O sberger M J, M cG arr N. Speech production characteristics of the hearing impaired. Speech and $L$ anguage: Advances in basic research and practice. 2012;8(12):221-83.

15. N ational Research Council (US) Committee on Disability Determination for Individuals with $\mathrm{H}$ earing Impairments; D obie RA, V an $\mathrm{H}$ emel S, editors. H earing L oss: D etermining Eligibility for Social Security Benefits. W ashington (DC): $\mathrm{N}$ ational Academies Press (US); 2004. 7, Hearing Loss in Children. Available from: https://www.ncbi.nlm.nih.gov/ books/N BK 207837/

16. $H$ amerschmidt $R, M$ oreira $A T, W$ iemes $G R$, T enório $S B$, $T$ âmbara $E M$, et al. Cochlear implant surgery with local anesthesia and sedation: comparison with general anesthesia. O tol N eurotol. 2013;2(11):23-27. 
17. H uttunen K, Rimmanen S, Vikman S, Virokannas N, Sorri M, Archbold S, et al. Parents' views on the quality of life of their children 2-3 years after cochlear implantation. Int J Pediatr O torhinolaryngol. 2009c;73(12):1786-94.

18. Chang C, Cho J-R, Liu H, Wagner RK, Shu H, Zhou A. Associations of phonological and morphological awareness with vocabulary \& word recognition in 2nd graders. J Exper Child Psych. 2015;92(2):140-60.

19. Prathiba DG. Benefits of cochlear implants in children with hearing impairment: Parental perspectives from tertiary care hospitals in Tamilnadu. Indian J Pub Health Res Dev. 2020;11(6). D OI.10.37506/ijphrd.v11i6.10596 